\title{
The e-Fran Program: A Nation-Wide Initiative Supporting Research Projects to Foster Learning and Teaching through Digital Technologies
}

\author{
Monique Grandbastien \\ LORIA, Université de Lorraine, France \\ monique.grandbastien@loria.fr
}

\begin{abstract}
This paper presents e-Fran, an on-going French initiative for linking academics from various disciplines and practitioners to design and test innovative ways of using digital technologies to improve learning outcomes. It is a research policy paper as first research results are not yet available. e-Fran is a nation-wide research program deployed in France from October 2016 over four years. The national context, the objectives, the project selection process and the funded projects are described as well as the follow-up actions.
\end{abstract}

Keywords. Digital plan for Education, research program, research funding policy, linking researchers and practitioners

\section{National context and challenges}

The technological revolution induced by digital technology is at the origin of major changes in our societies. The school must prepare students to integrate harmoniously into a society that has become digital. Bringing new ways of teaching and learning, digital technologies can also be an accelerator in educational success. Moreover the development of digital applications for education and training involve all the partners of education, including the players in the digital economy and, in particular, start-ups.

To face these major challenges, the French Ministry of National Education, Higher Education and Research [1] has adopted an ambitious strategy to make digital technology a factor in reducing inequalities. To improve the effectiveness of learning, to fight against dropping out, to develop the creativity of all and better prepare children to live and work as autonomous and responsible citizens in the society of tomorrow constitute the main axes of this ambition. Several initiatives brought this ambition into action, i.e. the public digital education service, whose mission is to organize and stimulate the provision of quality digital content and services to the entire educational community, the introduction of digital items in the curricula for all pupils aged from 6 to 16, the provision of many kinds of mobile devices, etc.

However, given the speed of changes, while deploying this policy, it is necessary to prepare the future. Indeed many questions remain unsolved, i.e. we encourage diversification of teaching practices using digital technology. Are all these practices successful? On the one end many papers report significant improvements [2] 3], but often they do not include very large scale evaluations over several years. On the other 
end, an OECD study [4] did not notice significant improvements among kids that were exposed to digital technologies, compared with kids that were less or not exposed. In this perspective, "improving education for the digital world" has been selected as a priority topic in the nationwide "Investments for the future" program [5]. This program supports innovative projects in several domains that are considered as key sectors for the future such as energy, ecology, health, etc., including research and education. It is directly piloted at the Prime Minister level and is running over a ten years period. In this framework, a program called e-Fran has been designed and the first call for projects launched in October 2015.

\section{Main innovative characteristics of the e-Fran program}

As an investment for the future, the e-FRAN program aims to support innovative experiments, using digital technology, developed within primary, secondary and high schools, based on the identification of "educational territories of digital innovation". It aims at stimulating the creation of a shared culture around the challenges of education for the digital society and to support projects that mobilize a variety of partners (school education institutions, local authorities, companies, research laboratories, associations, other actors involved in education), in a multi-stakeholder approach.

The e-Fran program is managed by a public financial partner, La Caisse des dépôts [6]. The maximum available total funding was $30 \mathrm{M€}$ for projects running over 4 years and providing from their own an equivalent amount of money. It is the first large-scale education research program run in France, bringing together school leaders and teachers, research teams, businesses and local authorities.

Prof. J.-M. Monteil, the e-Fran program leader, explains his views [7] as follows : "One of the problems of the school is the important school failure due to the diversity of children which the learning environment had to cover. Today, apprenticeships are mainly organized around logic-mathematical and verbal abilities, while the intelligence is multimodal. Numerous digital technologies, allowing, for example a plurality of contexts, make access to information more likely for a large number of learners, through more varied treatment and presentation situations. This possibility of enriching learning contexts and environments can significantly increase the supply and pedagogical responses of teachers. It then responds to the diversity of learning behaviors, cognitive and social characteristics of pupils, thus promoting the expression of not yet expressed capabilities.”1

It is a novel approach in the French National Education community, compared to previous initiatives [8] because it starts from the actors and includes them in the projects from the very beginning. The perspective is to qualify pedagogical practices and technological tools that support them by producing scientifically grounded results to create benchmarks for action and references that can be mobilized for teachers. Moreover it brings together people from the world of digital technology, scientists and educational practitioners who are too often working independently.

Furthermore, from a human resources view, it is expected that after 3 or 4 years of research at the heart of innovative educational practices, by a regular follow-up, a

1 Translated and adapted by the author 
community of actors, researchers and digital industries and the commitment of 36-40 doctoral students in the framework of the projects will ensure scientific continuity and innovation.

Consequently, the specifications of the e-Fran call for proposals were particularly demanding: The proposals should federate around an innovative project, primary and secondary schools, local authorities, companies, research laboratories, associations, other actors in education, etc. They should be anchored in a delimited experimental territory enabling precise monitoring and evaluation, in particular on the results of pupils engaged in experiments, and ensuring a fast adoption of the results among practitioners. They should meet well-defined objectives, whether they approach digital technologies as a pedagogical resource, new competence to be acquired, social fact and research object. They should demonstrate a high potential for transforming practices that can be replicated in other places.

\section{Results from the selection process}

Despite these strong requirements, more than 100 proposals were submitted and 22 projects were accepted. An independent jury, who was particularly careful to ensure that all criteria were met at a very high level, evaluated the proposals. In line with the expected multi-partners consortium, the jury included one third of the members from the academic sector, another third from the education sector and the final third from the business sector. Table 1 gives a detailed overview of the diversity and the wealth that can be found in the selected projects.

Table 1: Main figures related to the e-Fran call for projects

\begin{tabular}{|l|l|}
\hline $\begin{array}{l}\text { Number of projects submitted } \\
\text { (involving more than 1900 partners) }\end{array}$ & 105 \\
\hline $\begin{array}{l}\text { Number of projects selected } \\
\text { (involving more than 450 partners) }\end{array}$ & 22 \\
\hline Primary schools & 158 \\
\hline Lower secondary schools & 104 \\
\hline Higher secondary schools & 48 \\
\hline Research laboratories & 58 \\
\hline Teacher training institutes & 10 \\
\hline Higher education institutions (i.e. universities) & 25 \\
\hline Private companies & 20 \\
\hline Local public bodies (i.e. town or regional councils) & 24 \\
\hline Other bodies & 12 \\
\hline Total investment (of which 20 M€ awarded by the e-Fran program) & $\mathbf{4 0 ~} \mathbf{M €}$ \\
\hline
\end{tabular}

The projects started between October 2016 and January 2017 for a period of four years. The average funding of a project is $€ 1 \mathrm{M}$ supplemented by equivalent funding from partners.

For most projects, the research part includes funding for $\mathrm{PhD}$ and post-doc students (over 3 years). So $42 \mathrm{PhD}$ students and 15 post-doc students or research associates are 
funded through the program, mostly in cognitive sciences, but also in education sciences, in computer science, in didactics, etc.), they are working in research units in close relation with schools and we consider this new research taskforce as a first achievement of the program. We provide hereafter some examples of accepted projects.

e-P3C: How to address the diverse needs and strengths of students in the classroom, building on experimental psychology findings to develop a new Intelligent Tutoring System (ITS)? Proposed approach: This project aims at developing a new ITS offering each student different paths (gamified, abstract, context-based) to learn the same lesson. 40 teachers and inspectors (in charge of teacher training and evaluation) have been producing new teaching materials to build these different paths. An EdTech startup is developing the ITS. A large-scale randomized control design will include 8000 students from lower-secondary schools. Students in the treatment group will practice first mathematics and science with the ITS, whereas control group students will be taught either in a traditional way or using innovative non-digital teaching methods (Main à la Pâte). A huge amount of data will be collected through the ITS - together with paper-based pretests-posttests - to allow cognitive and social psychologists to assess and improve the impact of the ITS. Data analysis will also help to understand cognitive processes underlying learning, using students' logs.

FLUENCE: How to train pupils' fluency to support their reading and spelling? Proposed approach: This project aims to develop a Learning Management System offering specific devices to train fluency, adjust student practice to their needs (adaptive learning algorithm) and allow teachers to track individual progress (dashboard). These devices include a serious game "EVAsion" and an audiobook "Lectra", designed by three research teams (cognitive psychologists, neuroscientists, linguists) to help building prerequisite skills for fluency in reading in the short term. Later on, higher levels of fluency are expected to foster written comprehension and spelling. This project addresses both $6 y$-o pupils to support their learning of reading, and 11 y-o weak readers as a remedial education strategy. The local Espé (teacher training centre) is a key partner of this project and both methods and findings from this research project will be shared with future teachers.

SILVA NUMERICA: How to foster practical learning in vocational studies (forestry field)? Proposed approach: This project targets vocational high schools offering the "forest-wood" training track. It aims to design a virtual and augmented reality platform: forestry professionals as well as high school teachers will work together to develop this virtual forest environment with features matching the national curriculum. Immersive learning is expected to improve students' skills and to foster interest and dedication to learning. An education research takes part in the project and will help design the platform in a way that is conducive to learning, as well as assess the impact of virtual reality on learning for each student.

Some readers may object that the call for projects should have targeted a few major issues. This was not the case: the call was open to any theme as long as it was a research project on learning with digital technologies, involved a diversity of stakeholders (teachers, school management, tech and edtech companies, non-profit, local authorities, etc.). Priority was given to ambitious projects, no matter their focus. This may account for shortcomings in the diversity of selected projects, as important 
topics may not be addressed / others might be addressed in two or three different projects.

\section{The e-Fran program follow-up}

A program follow-up has been set up in order to establish efficiency criteria and to ensure the success of these investments. In a rapidly evolving context, we have to foster networking and cross fertilization of projects as well as agile adaptation to further needs. Project leaders will meet on a regular basis.

A first big challenge is to give birth to a new generation of scientists used to work at the crossroads of high quality scientific research and close collaboration with practitioners. In that perspective summer schools will be organized among $\mathrm{PhD}$ students funded by the program. These students belong to different labs, they work in different disciplines, but they share the same goal: better understanding the effects of digital technologies to enhance learning in a digital society and they bring complementary views which allow better results than isolated ones. Another facet of the same challenge is to give birth to a new generation of teachers, teacher trainers and other staff members who are convinced that there is no efficient innovation without close links with academic partners.

Another challenge is to associate partners who do not yet belong to the selected projects, in order to maximize the expected dissemination. A first direction is to associate new regions for covering all the country, for instance for early experimentations. Another direction is to associate private companies to allow them an early understanding of the kind of business they can develop to fulfil the educational sector's needs as they emerge from the projects.

\section{Conclusion and future work}

e-Fran is a large-scale initiative set up by the French state to finance innovative and promising investments for digital education in the country. It raises high expectations and should bring answers at the level of these expectations. Scientific findings will be published at the international level as usual. Processes and results have to be compared with initiatives from other countries in the same domain, i.e. IT curricula changes in UK [9]. However integrating the results into practices needs to take into account the cultural factors that play an important role in education. So the results have to be considered together with the innovative participatory processes adopted in the projects.

Acknowledgments. The author would like to thank J-M. Monteil for his inspiring documents, G. Leroux for her help in the figures of the program and all the members of the evaluation and piloting committees for fruitful discussions. 


\section{References}

1 Ministère de l'Education, Plan numérique, http://ecolenumerique.education.gouv.fr/plannumerique-pour-l-education/, (2017)

2 De Freitas S., Are games effective learning tools? A review of educational games, Journal of Educational Technology \& Society, (to appear, 2017)

3 Outhwaite L. A., Gulliford A., Pitchford Nicola J., Closing the gap: Efficacy of a tablet intervention to support the development of early mathematical skills in UK primary school children, Computers \& Education, 108, 43-58, (2017)

4. OECD, Students, Computers and Learning Making the Connection, available at http://www.oecd.org/publications/students-computers-and-learning-9789264239555en.htm, (2015)

5 Commissariat Général à l’Investissement, Programme d'investissements d'avenir, http://www.gouvernement.fr/investissements-d-avenir-cgi (2017)

6 Caisse des dépôts, http://www.caissedesdepots.fr/espaces-de-formation-de-recherche-etdanimation-numeriques-e-fran, (2017)

7 Monteil J-M. Interview, http://www.reseau-espe.fr/actualites/appel-projet-e-fran-interviewde-jean-marc-monteil, (2016)

8. Baron, G.-L., Drot-Delange, B., Grandbastien, M., and Tort, F. Computer science education in French secondary schools: Historical and didactical perspectives. ACM Trans. Comput. Educ. 14, 2, Article 11, 27 p., (2014)

9 Sentance S. et al., Grand challenges for the UK : Upskilling teachers to teach Computer Science within the Secondary curriculum, https://www.academia.edu/2456347/Grand_challenges_for_the_UK_Upskilling_teachers_t o_teach_Computer_Science_within_the_Secondary_curriculum (2012) 